\title{
DarkCideS 1.0, a global database for bats in karsts and caves
}

Krizler C. Tanalgo ${ }^{1}$, John Aries G. Tabora ${ }^{2}$, Hernani Fernandes Magalhães Oliveira ${ }^{3}$, Danny Haelewaters ${ }^{4}$, Chad T. Beranek ${ }^{5}$, Aída Otálora-Ardila ${ }^{6}$, Enrico Bernard ${ }^{6}$, Fernando Gonçalves $^{7}$, Alan Eriksson ${ }^{8}$, Melissa Donnelly ${ }^{9}$, Joel Monzón González ${ }^{10}$, Humberto Fernandez Ramos ${ }^{11}$, Alberto Clark Rivas ${ }^{11}$, Paul W. Webala ${ }^{12}$, Stanimira Deleva $^{13}$, Ridha Dalhoumi ${ }^{14}$, Jaycelle Maula ${ }^{15}$, Dennis Lizarro ${ }^{16}$, Luis F. Aguirre ${ }^{17}$, Nils Bouillard $^{18}$, Ma. Niña Regina M. Quibod ${ }^{19}$, Jennifer Barros ${ }^{6}$, Manfredo Alejandro Turcios-Casco $^{20}$, Marcio Martínez ${ }^{20}$, Diego Iván Ordoñez-Mazier ${ }^{20}$, José Alejandro Soler Orellana $^{20}$, Eduardo J. Ordoñez-Trejo ${ }^{20}$, Danny Ordoñez ${ }^{20}$, Ada Chornelia ${ }^{1}$, Jian Mei $\mathrm{Lu}^{1}$, Chen Xing ${ }^{21}$, Sanjeev Baniya ${ }^{22}$, Renata L. Muylaert ${ }^{23}$, Leonardo Henrique Dias-Silva $^{24}$, Nittaya Ruadreo ${ }^{25}$, and Alice Hughes ${ }^{1}$

${ }^{1}$ Landscape Ecology Group, Center for Integrative Conservation, Xishuangbanna Tropical Botanical Garden, Chinese Academy of Sciences, Yunnan, P.R. China ${ }^{2}$ Department of Biological Sciences, College of Science and Mathematics, University of Southern Mindanao, North Cotabato, Philippines

${ }^{3}$ Department of Zoology, Federal University of Paraná, Curitiba, PR, Brazil

${ }^{4}$ Research Group Mycology, Department of Biology, Ghent University, 9000 Ghent, Belgium; Operation Wallacea Ltd, Wallace House, Old Bolingbroke, Lincolnshire, PE23 4EX, United Kingdom; Faculty of Science, University of South Bohemia, 37005 České Budějovice, Czech Republic

${ }^{5}$ School of Environmental and Life Sciences, Biology Building, University of Newcastle, University Drive, Callaghan NSW 2308, Australia; FAUNA Research Alliance, PO Box 5092, Kahibah, NSW 2290, Australia

${ }^{6}$ Grupo en Conservación y Manejo de Vida Silvestre, Universidad Nacional de Colombia, Colombia; Laboratório de Ciência Aplicada à Conservação da Biodiversidade, Department of Zoology, Universidade Federal de Pernambuco (UFPE), Brazil ${ }^{7}$ Department of Biodiversity, Institute of Bioscience, Universidade Estadual Paulista (UNESP), Rio Claro, São Paulo, Brazil; Conservation Science Group, Department of Zoology, University of Cambridge, Cambridge, UK

${ }^{8}$ Programa de Pós-Graduação em Ecologia e Conservação, Instituto de Biociências, Universidade Federal de Mato Grosso do Sul, Campo Grande, Brazil ${ }^{9}$ Proyecto CUBABAT, Calle América 6503 (Altos) e/ Jáuregui y Santa Isabel. 40100, Matanzas. Cuba

${ }^{10}$ Proyecto CUBABAT, Calle América 6503 (Altos) e/ Jáuregui y Santa Isabel. 40100, Matanzas. Cuba; Fundación "Antonio Núñez Jiménez" de la Naturaleza y el Hombre, Calle 5ta B, No. 6611 e/ 66 y 70, Miramar, Playa, La Habana Cuba; Sociedad Espeleológica de Cuba (SEC), Calle 9na. 8402 e/ 84 y 84ª . Playa. La Habana, Cuba ${ }^{11}$ Proyecto CUBABAT, Calle América 6503 (Altos) e/ Jáuregui y Santa Isabel. 40100, Matanzas. Cuba; Sociedad Espeleológica de Cuba (SEC), Calle 9na. 8402 e/ 84 y 84ª Playa. La Habana, Cuba

${ }^{12}$ Department of Forestry and Wildlife Management, Maasai Mara University, Narok, Kenya

${ }^{13}$ Sede del Sur, Universidad de Costa Rica, 4000 Alamedas, Golfito 60701, Costa Rica; 
National Museum of Natural History-Bulgarian Academy of Sciences, Sofia, Bulgaria

${ }^{14}$ Laboratoire de Biosurveillance de l'Environnement, Faculté des Sciences de Bizerte, Université de Carthage, 7021 Zarzouna, Tunisia

${ }^{15}$ Department of Biology, Southern Luzon State University, Lucban, Quezon, Philippines

${ }^{16}$ Centro de Investigación de Recursos Acuáticos, Universidad Autónoma del Beni "José

Ballivián" (CIRA-UABJB). Campus "Dr. Hernán Melgar Justiniano", Santísima

Trinidad, Beni, Bolivia; Programa para la Conservación de los Murciélagos de Bolivia.

Cochabamba y Beni, Bolivia

${ }^{17}$ Programa para la Conservación de los Murciélagos de Bolivia. Cochabamba y Beni, Bolivia; Centro de Biodiversidad y Genética, Universidad Mayor de San Simón, Casilla 538, Cochabamba, Bolivia

${ }^{18}$ Barbastella Echology, Gentpoortstraat 50, 9800 Deinze, Belgium

${ }^{19}$ Center for Conservation Biology, Core Botanical Garden, Chinese Academy of

Sciences, Yunnan, P.R. China; International College of the Chinese Academy of

Sciences, Beijing, P.R. China; Museum of Natural History of the University of the

Philippines, Los Banos, Laguna, Philippines

${ }^{20}$ Asociación para la Sostenibilidad e Investigación Científica en Honduras (ASICH).

Barrio La Granja, entre 28 y 29 calle, C. P. 504. Comayagüela M.D.C. Francisco

Morazán, Honduras

${ }^{21}$ School of Zoology, Faculty of Life sciences, Tel Aviv University, Tel Aviv, Israel

${ }^{22}$ National Centre for Biological Sciences (NCBS), Bangalore, India

${ }^{23}$ Molecular Epidemiology and Public Health Laboratory, Hopkirk Research Institute, Massey University, Palmerston North, New Zealand

${ }^{24}$ Laboratório de Mastozoologia do Departamento de Biologia Animal da Universidade Federal de Viçosa, Minas Gerais - Brasil

${ }^{25}$ Division of Biological Sciences, Faculty of Science, Prince of Songkla University, Hat Yai, Songkhla, Thailand

November 1, 2021

\begin{abstract}
Understanding biodiversity patterns as well as drivers of population declines, and range losses provides crucial baselines for monitoring and conservation. However, the information needed to evaluate such trends remains unstandardised and sparsely available for many taxonomic groups and habitats, including the cave-dwelling bats and cave ecosystems. Here, we present the DarkCideS 1.0, a global database of bat caves and bat species based on curated data from the literature, personal collections, and existing datasets. The database contains information for geographical distribution, ecological status, species traits, and parasites and hyperparasites for 679 bat species known to occur in caves or use caves in their life-histories. The database contains 6746 georeferenced occurrences for 402 cave-dwelling bat species from 2002 cave sites in 46 countries and 12 terrestrial biomes. The database has been developed to be a collaborative, open-access, and userfriendly platform, allowing continuous data-sharing among the community of bat researchers and conservation biologists. The database has a range of potential applications in bat research and enables comparative monitoring and prioritisation for conservation.
\end{abstract}

\title{
Background and Summary
}

Human civilization has left its footprint on every part of the planet, in the process driving what is frequently referred to as the sixth mass extinction ${ }^{1,2}$. Conservation prioritisation requires a rigorous assessment of vulnerable species as well as their habitats to develop effective priorities for conservation. 
However, the data needed to develop such priorities with rigour are often lacking. Biodiversity integration and synthesis is an important empirical step to identify priorities in maximising the already limited funds allocated to conservation ${ }^{3}$. The diversity and distribution of a subset of terrestrial vertebrates have become an umbrella for taxonomic and spatial conservation, despite the known biases present in popular open datasets ${ }^{4,5}$. Efforts to mitigate extinction risks or protect key habitats often disproportionately focus on particular taxa, ecosystems, or regions ${ }^{6,7}$. This approach neglects many other equally important species and their habitats and compromising the maintenance of ecosystem services provided by diverse functional groups ${ }^{8,9}$.

There are more than 1400 known extant bat species distributed across almost all terrestrial habitats around the globe ${ }^{10,11}$. Many of these species occur in biodiversity hotspots that are threatened by both anthropogenic and natural threats ${ }^{6}$. Caves are key habitats for bats ${ }^{12}$ but are nonetheless threatened and in need of conservation; despite hosting high endemism, cave ecosystems receive little attention in terms of fund allocation for scientific studies and conservation compared to their surface counterparts such as agricultural and forest ecosystems ${ }^{11-14}$. Cave taxa are adapted to light-limited underground environments and most of them are dependent on mobile species such as bats to transport organic nutrients into these environments ${ }^{15,16}$. Bats are keystone species in karst ecosystems and ideal cave conservation surrogates, delivering vital energy sources into caves as they regularly forage from outside ecosystems. Cave ecosystems are critical for bats, with around half of all bat species reliant on caves, with a high rate of endemism and proportion of threatened species facing high risks from varying threats ${ }^{17}$. Nevertheless, conservation attention towards cave-dwelling bats remains limited compared to other mammalian taxa. Thus, there is an urgent need for better data to develop effective priorities for bats ${ }^{11}$.
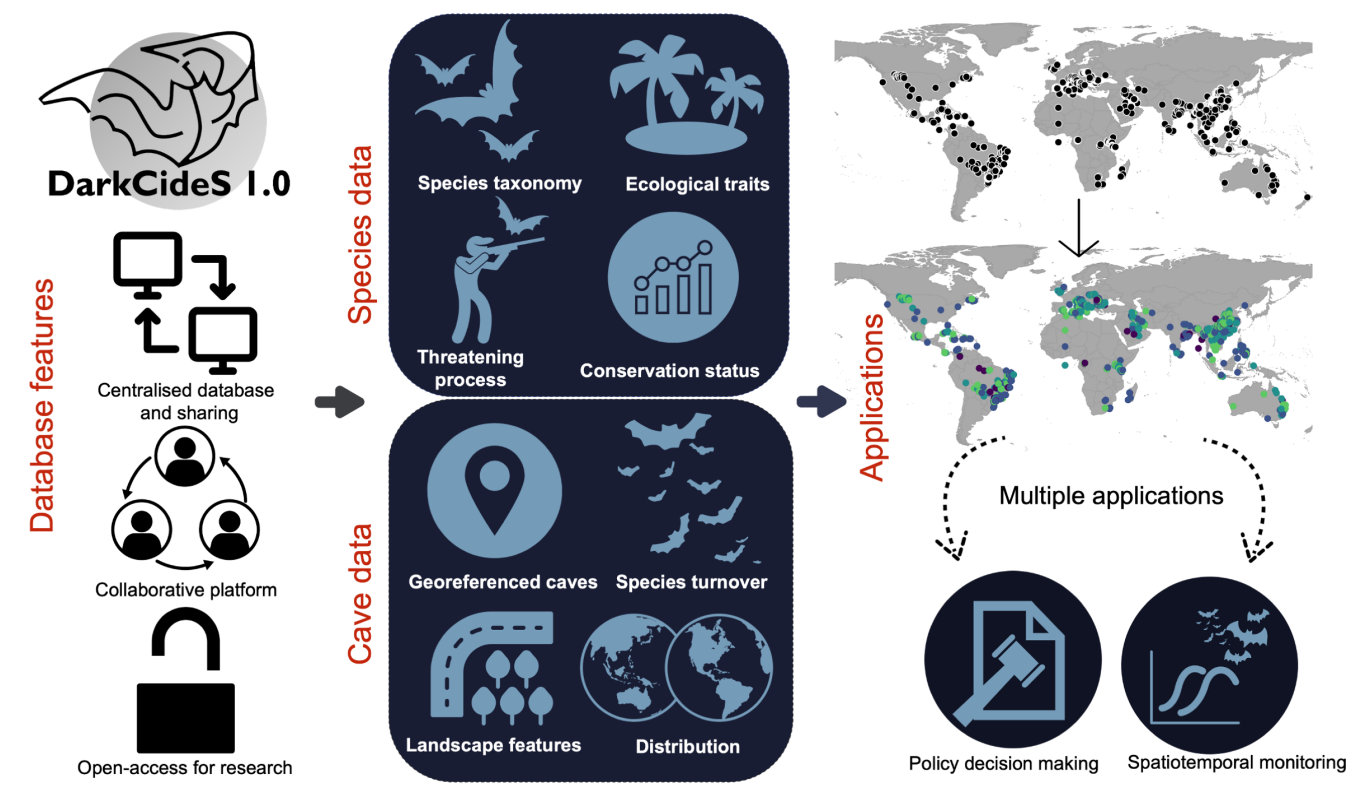

Figure 1: A schematic diagram showing the features, contents, and potential applications of the DarkCideS 1.0 database. The database is a centralised, collaborative, and open-access platform that contains information on cave-dwelling bats species and their distribution.

Effective conservation decision-making relies on the accuracy and precision of the data used to design priorities $^{7,18}$. Identifying priority caves for conservation requires an understanding of species diversity, endemism patterns, interactions with other organisms, and threats within and outside these systems ${ }^{19}$. Additionally, while numerous organisations and collaborative efforts aim to database bat distributions, comprehensive and specific datasets for cave-dwelling bats, including their distributions and ecological traits, are currently lacking. Large databases for species distributions such as the Global Biodiversity Information Facility (GBIF) exist and openly provide distribution data for bats. However, due to the enormous amount of information within these databases, it is challenging to selectively evaluate data for specific ecosystems such as caves, and thus more specialist datasets are needed to facilitate appropriate 
habitat-based prioritisation.

To address this knowledge gap, we created DarkcideS 1.0, A global database for bats in karsts and caves to advance global bat cave vulnerability and conservation mapping initiatives. The creation of the dataset primarily aims to map and digitise the distribution of cave-dwelling bats to facilitate the assessment of their vulnerability to landscape threats. DarkCideS 1.0 represents a publicly available database of cave-dwelling bats across time and space including their estimated population (e.g., counts), geographical distribution (latitude and longitude), ecological traits, levels of endemism, conservation status, and threatening processes. The purpose of the DarkCideS 1.0 initiative is to centralise and develop an open-access platform for information exchange among bat researchers and conservation biologists to advance the development of targeted conservation measures and macroecological studies (Figures 1, 5). Potential applications of the database include assessing species conservation status and extinction risks; understanding drivers of extinction, cave conditions, and landscape threats; accurately developing species distribution models; and determining long-term cave conservation priorities at regional to global scales.

\section{Methods}

The DarkCideS database was initially conceptualised and developed by KCT, JAG, and ACH as part of the "Global Bat Cave Vulnerability and Conservation Mapping Initiative" in 2014, and later with the "Mapping Karst Biodiversity in Yunnan" and the "Southeast Asian Atlas of Biodiversity" projects. The initiative includes developing tools and methods (e.g., the Bat Cave Vulnerability Index ${ }^{20}$ ) and synthesis (e.g., the global bat cave vulnerability assessment ${ }^{17}$ ) to identify conservation priorities and important bat caves in the tropics. Since 2019, the initiative has expanded and potential collaborators and contributors were invited through scientific conferences (Association for Tropical Biology and Conservation 2018, International Bat Research Conference 2019), social media platforms, and personal correspondences. At present, the database has 36 collaborators from twenty countries on six continents with expertise and research interests in bat conservation. Four main datasets for all known cave-dwelling bats were built for the DarkCideS database version 1.0.

\section{Datasets and compilation for species checklist (Dataset 1)}

The first dataset contains taxonomic checklists for all extant cave-dwelling bats species extracted from the expert-based International Union for the Conservation Union (IUCN) Red List database version 2020.1 (Table 1). We screened and included all bat species that were reported to use, roost in, or aggregate in "Caves", "Underground", and "Karsts" habitats in any part of their life histories. We also scanned major bat cave databases from expeditions such as "Bats in China" (http://www.bio.bris. ac.uk/research/bats/China/) and UNEP-EUROBATS (https://www.eurobats.org/) for European bats $^{21}$. In addition, the first dataset contains species ecological traits, distribution range, and threatening processes. 

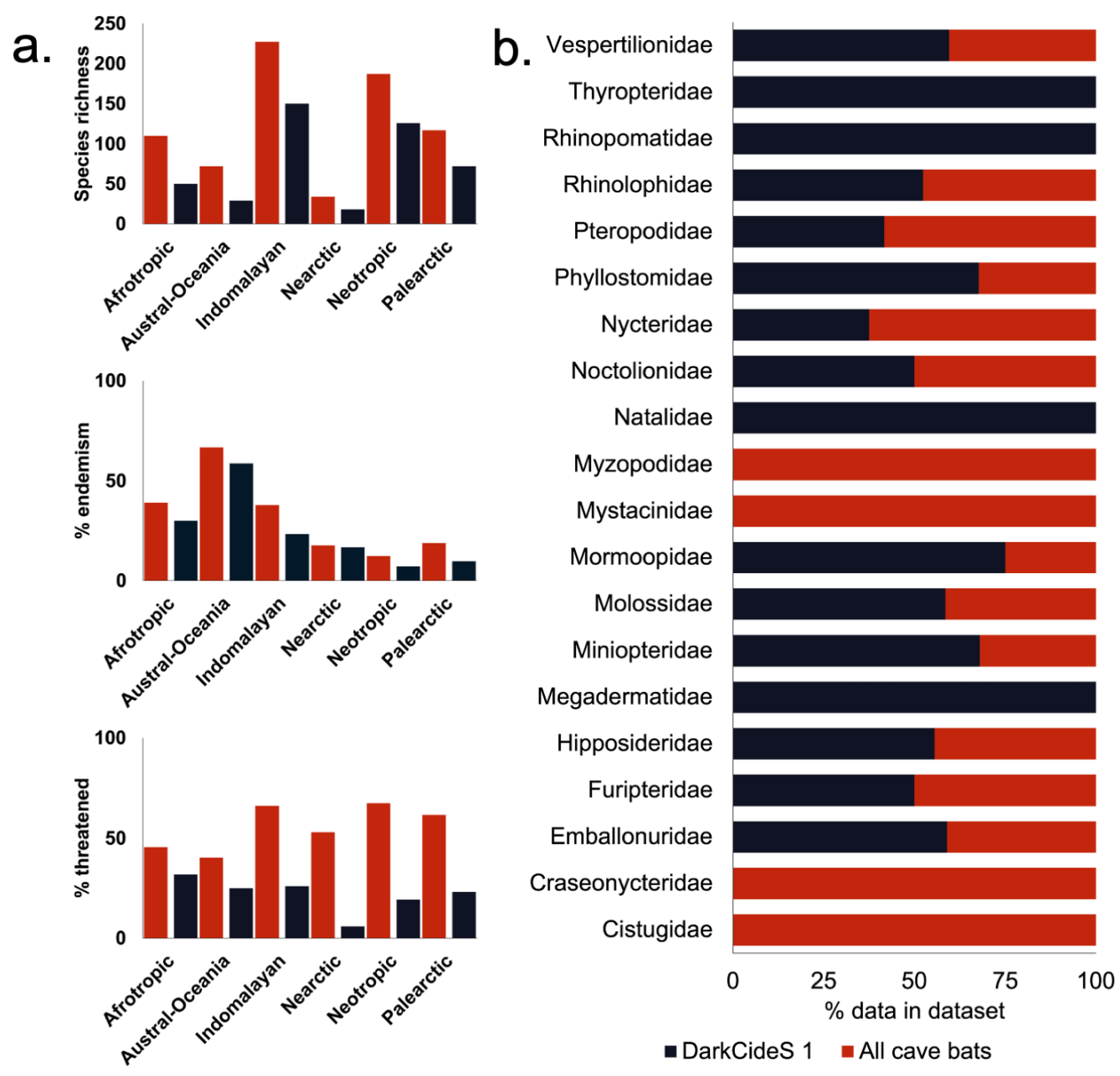

- DarkCides 1 All cave bats

Figure 2: Biogeographic (a) and family-level (b) comparison of species turnover between IUCN estimates (red bars) and sampled caves from DarkCideS 1.0 (black bars) species richness, the proportion of endemism, and proportion of threatened species worldwide.

\section{Habitat preference, distribution, ecological status, and traits (Dataset 1)}

We classified species distribution by biogeographical realm (Indomalaya, Austral-Oceania, Afrotropical, Neotropical, Palearctic, and Nearctic) and terrestrial biomes following Olson et al. ${ }^{22}$. We described species major habitat breadth based on IUCN Level 1 classification https://www.iucnredlist.org/ resources/habitat-classification-scheme (Caves, Forests, Savanna, Desert, Urban, Artificial, and Wetlands). Species current conservation status (Data Deficient, Least Concern, Near Threatened, Vulnerable, Endangered, and Critically Endangered) and population trends (e.g., Unknown, Decreasing, Stable, Increasing) were categorised using standard IUCN Red List assessments. Using the same criteria, we categorised species endemism as geopolitically endemic (e.g., country-endemic, and non-endemic) when a species occurs only in a single country or state territory ${ }^{23}$, and island endemism was classified as island-restricted or predominantly mainland ${ }^{24}$. The highest country endemism was in the Eastern Hemisphere with the highest in the Austral-Oceania (40\%) region, followed by the Afrotropics (21\%), then the Indomalayan region (16\%). However, the highest proportion of threatened species, was in Indomalayan $(43 \%)$ and the Neotropics (22\%) (Figure 2c).

Furthermore, species current geographical ranges were compiled from the Phylacine 1.2 database ${ }^{24}$ based on species IUCN ranges. Three species traits were included: the adult body mass (in grams) per species were derived from Phylacine $1.2^{24}$ and generation length from Pacifici et al. ${ }^{25}$. For trophic groups, we derived diet information from EltonTraits $1.0^{26}$. We grouped species as frugi-nectarivorous for 
all species that forage on plant-based resources (e.g., frugivores and nectarivores). As species foraging smaller vertebrates (i.e., fish and rodents) are very few, we classified them as carnivores along with insectivorous bats. Species that forage on both resources were grouped into omnivores (Table 1).

\section{Species threatening process (Dataset 1)}

We identified potential threats for each bat species listed in the checklist using the information from the IUCN Red List assessments (version 2020.1) in addition to threats highlighted in the literature. The IUCN Red List standardised its classification based on Salafsky et al. ${ }^{27}$, but we reclassified the threatening process into three key categories: Direct, Indirect, and Natural (Table 1) based on the drivers of threat ${ }^{12,20,28}$. Direct threats $\left(T_{\text {dir }}\right)$ refer to the threats or risks that are direct to or in cave systems with immediate and perceivable impacts on populations or behaviour of species. This category includes direct human impacts (e.g., persecution, eviction, and cave closures) and the use of caves for harvesting bats, tourism, religious visits, and mining (minerals or guano). Indirect threats $\left(T_{\text {ind }}\right)$ refer to the threats outside cave systems or within cave proximity, of which the impacts to populations are secondary or non-immediate but otherwise detrimental. Examples include deforestation, agriculture, and urbanisation. Lastly, Natural threats $\left(T_{\text {nat }}\right)$ refer to threats that are natural in origin, though their frequency may be impacted by human activities, and that may directly or indirectly impact populations, such as diseases and climate-driven risks (e.g., drought, extreme cold) (Table 1). 
a.

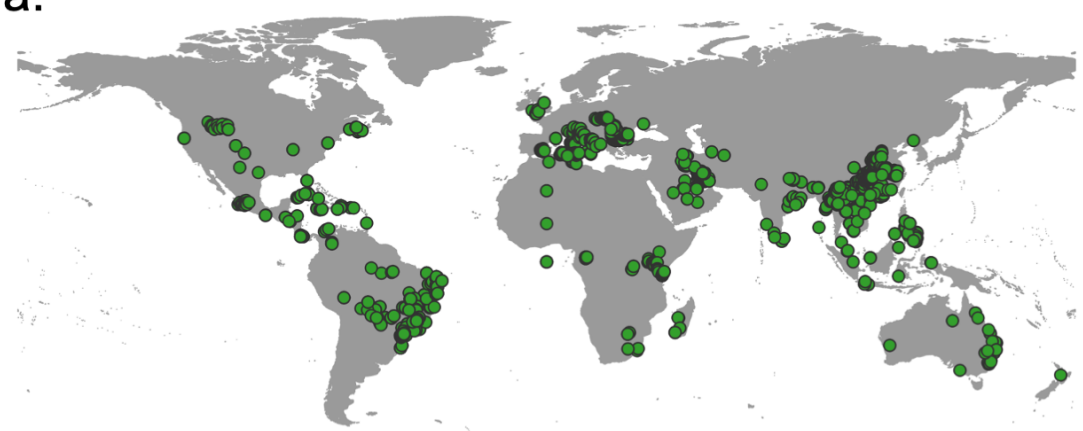

b.

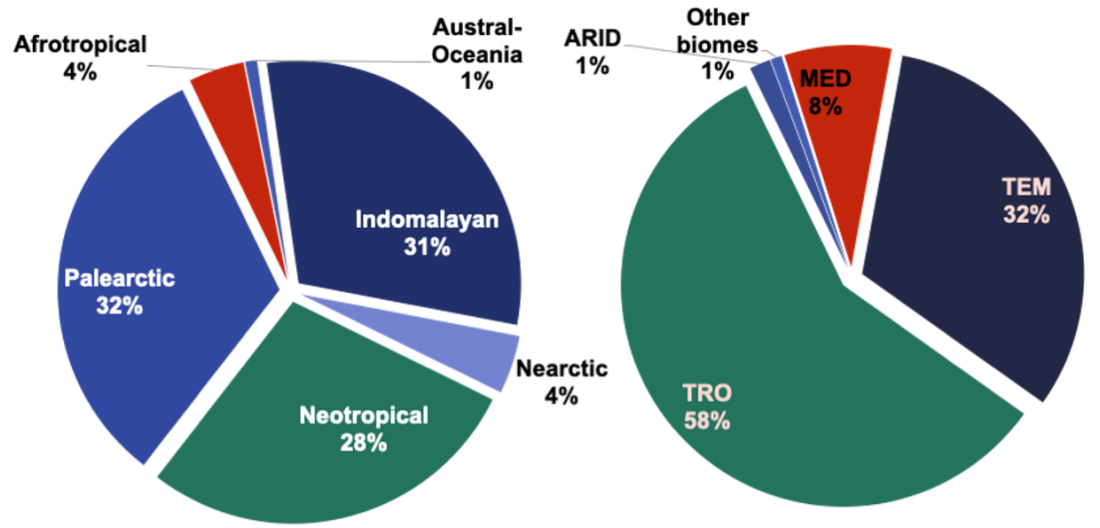

C.

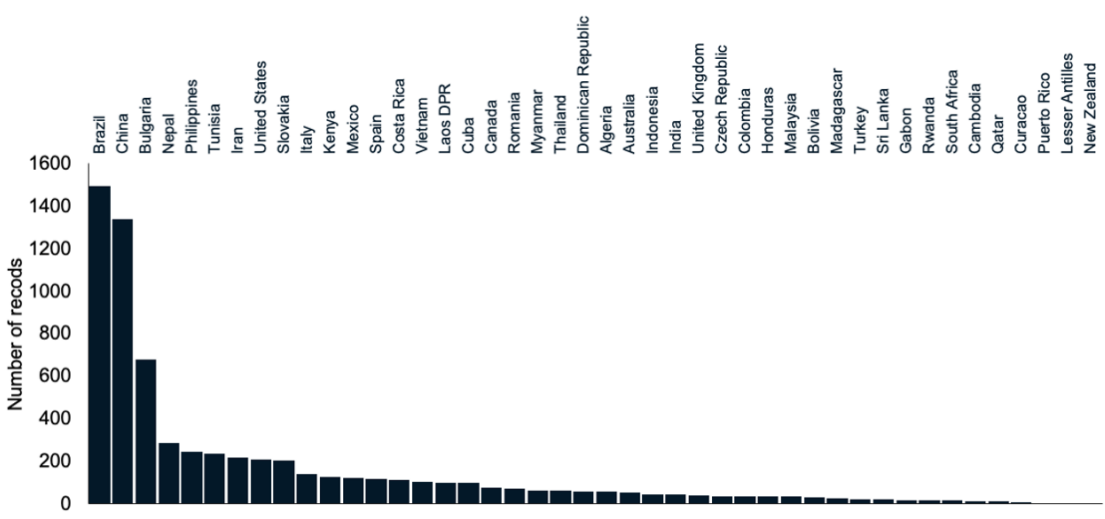

Figure 3: The geographical data turnover of the current database version: (a) geographical locations of all bat caves included in the database, (b) percent distribution of species occurrence in terms of the biogeographical realm (left) and terrestrial biome (right), (c) country-level turnover.

\section{Bat cave georeferencing (Dataset 2)}

The second dataset contains the bat cave geographical location (latitude/longitude) and recorded species (Table 2, Figure 3A). We used the Web of Science and Google Scholar to search online literature, databases, and repositories for published information on cave-dwelling bats from 1990 to 2021. We used the following combination of keywords: (Bat* OR Chiroptera OR Chiroptera fauna*) AND (Diversity OR "Species richness" OR abundance OR distribution OR conservation OR ecology) AND (Cave* OR Cave-dwelling OR Cave-roosting OR underground* OR subterranean OR karst* OR Limestone). We also set a "create alert" in Google Scholar whenever new related papers were published. The data mining process for version 1.0 ended in June 2021. Our search returned 753 papers. We also searched using the 
Baidu Research engine for Chinese literature and self-archived ResearchGate to maximise search results. To ensure the precision of the datasets included in DarkCideS 1.0, we filtered all published literature to only include those papers or reports with complete species names and geographical records. We contacted corresponding authors with requests to provide us with geographical data when these were missing from their papers or supplementary materials. In the circumstance that we were unable to find the data, and the corresponding author did not respond to our request, that "cave site" was excluded from the database. We converted all species and cave latitude and longitude into WG8 84 decimal degrees with five significant figures. The second dataset of DarkCideS 1.0 contains 6746 georeferenced occurrences for 402 species ${ }^{17}$ from 2002 cave sites (Figures 3). Cave sites occur in all continents except Antarctica, with most of the data originating from tropical and temperate biomes (Figure 3B). We have cave records from 46 countries of which China and Brazil have the highest number of caves recorded (Figure 3C).

\section{Cave landscape features and vulnerabilities (Dataset 3)}

The condition of surface ecosystems and the extent of threats are significant determinants of cave-dwelling bat diversity. Yet, standardising the vulnerability of caves and underground ecosystems from threats on a global scale is challenging. To address this, the surface ecosystem was mapped as a proxy to assay cave vulnerability to threats using remotely-sensed landscape features. The third dataset included in the database contains the measured land-use and landscape features of the cave surroundings using the georeferenced data from the second dataset (Table 3, Figure 4). The selected landscape features measurements of the 2002 cave sites were selected based on Tanalgo et al. ${ }^{17}$. We included the estimated distance and measures of twelve $(N=12)$ landscape variables in the database including canopy cover height ${ }^{29}$, tree density ${ }^{30}$, distance to bodies of water ${ }^{31}$ bare ground cover change ${ }^{32}$, short vegetation cover change $^{32}$, tall tree cover change ${ }^{32}$; for vulnerabilities we included distance to urban areas ${ }^{32}$, distance to roads $^{33}$, mine density ${ }^{34}$, night light ${ }^{35}$, relative pesticide exposure ${ }^{36}$, and population density ${ }^{37,38}$. For distance variables, the "distance to feature" tool was used in ArcMap 10.3 and distances were mapped at a $1-\mathrm{km}$ resolution.

\section{Cave bat parasites and hyperparasites (Dataset 4).}

Parasites, while being among the most diverse modes of life, are often disregarded in conservation strategies $^{39}$. It is well established that parasites affect the stability of food webs and ecosystem health, but hyperparasites have thus far been severely understudied. For future studies on host associations across multiple trophic levels and on the effects of climatic conditions and land-use changes, parasites and hyperparasites are part of our DarkCideS 1.0 database. The fourth dataset lists the parasitic bat flies and their Laboulbeniales fungal hyperparasites associated with cave bats. Data were collected from several sources, including our own fieldwork ${ }^{36}$, Haelewaters et al. ${ }^{40}$, and de Groot et al. ${ }^{41}$. Bat fly taxonomy followed Dick and Graciolli ${ }^{42}$ and Graciolli and Dick ${ }^{43}$ and fungal taxonomy followed Index Fungorum ${ }^{44}$. In addition to the conspicuous bat flies, bats are host to several other lineages of parasites mites and ticks, lice, fleas, bugs, and earwigs ${ }^{45,46}$. Consequently, the fourth dataset will be expanded on in future versions of DarkCideS with data on these parasitic organisms. A recent call for global collaborations among bat scientists and collaborations to generate multitrophic data of bats, bat flies, and fungi ${ }^{45}$ along with the current DarkCideS 1.0 initiative will contribute to a general understanding of how ecological and life-history traits are correlated with bat parasitism and how host associations may change under changing conditions. 

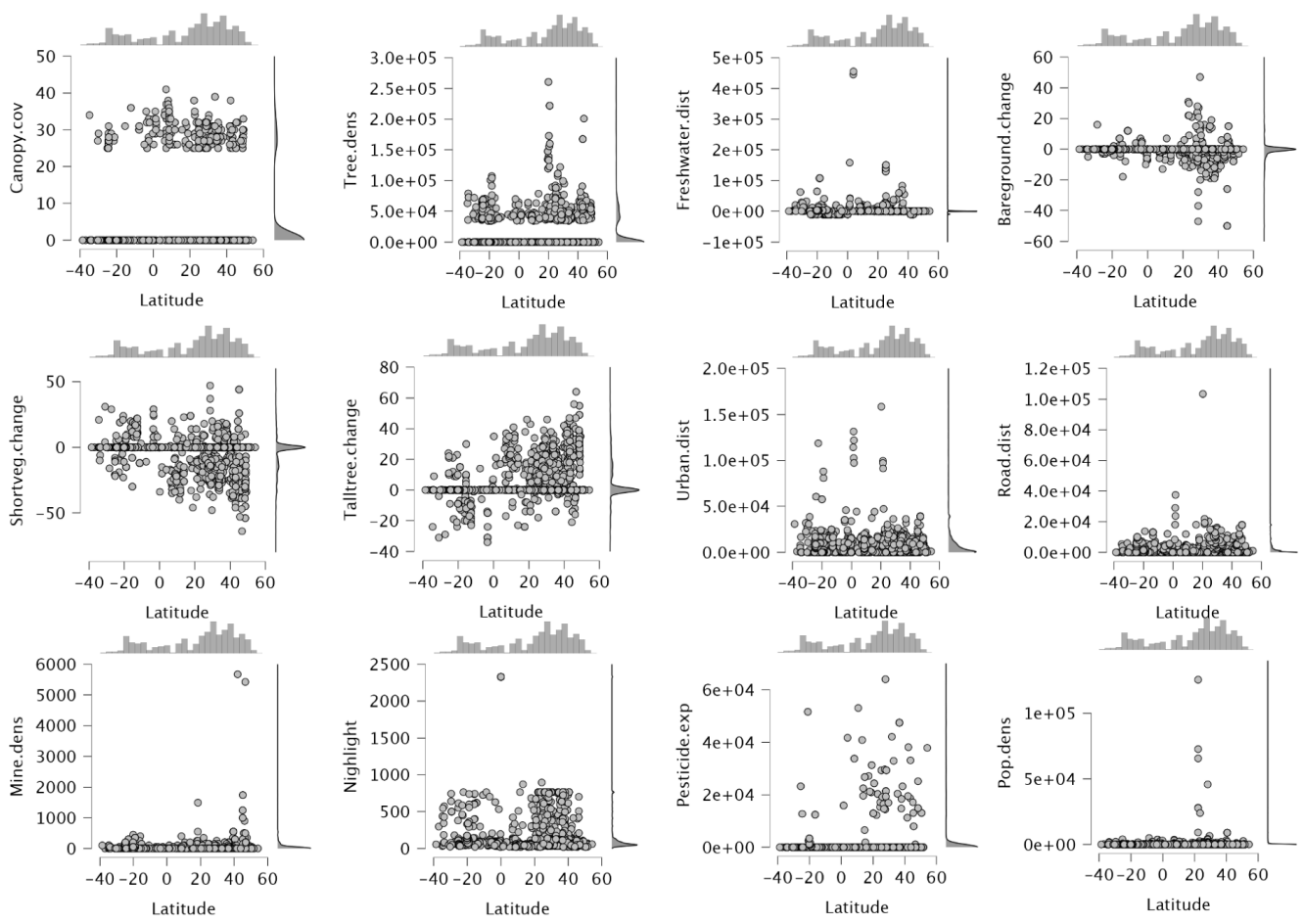

Figure 4: Density and latitudinal distribution of bat caves based on different landscape features and vulnerability (for units of each landscape feature, please refer to the original data sources, Table 3).

\section{Data Records}

The complete database for global cave-dwelling bats was organised in four main datasets stored in separate Excel workbooks (.csv file format). Each dataset contains unique sequential name IDs that correspond to metadata, variables, and references. All datasets included in the database are available and open-access on the figshare online repository (links will be included after final review) and through a public web page (https://darkcides.org/). The resolution of the publicly available cave and species occurrences were reduced for the protection of caves and to prevent hunting and harvesting. Database users can request high-resolution data of georeferenced species occurrence and cave sites from the corresponding authors.

\section{Technical Validation}

The data included in this database are mainly derived from expert-based databases, published material and bat researchers, therefore ensuring the accuracy of the included data. We provided the corresponding reference (when applicable) for each cave record for cross-referencing and data validation purposes. When published "cave datasets" were unclear or lacked detailed information, we contacted the corresponding authors. We encourage continued contributions to the DarkCideS database as we aim to regularly update the entries for species checklists, traits, geographical locations of caves, and species occurrence data. For species ecological status (e.g., current conservation status, population trends, geopolitical endemism), we will update entries after every IUCN Red List assessment cycle. Datasets that were originally entered as "unpublished" or "personal data" will also be updated after the respective author or contributor has published their findings. The database will be updated when new data are contributed and will be corrected when an error in the data entries are reported to any of the corresponding authors. Quality screening of new entries based on the criteria listed above will be made before adding new 
records to the database (Figure 5). Once an update is made, a release note will be published on the database website. When updating new versions of DarkCideS, we will continue to make available previous releases. Contributors will be included as co-authors when the next version of the database is published. Furthermore, as each cave has a unique ID, additional surveys of other taxa at the same locality can be integrated into the database, to provide a backbone for enhancing our understanding of cave biodiversity through time.

\section{Usage Notes}

Users should cite this publication when using the DarkCideS 1.0 database and future version releases, especially when using the georeferenced data of caves and bat species. Although we aim to maximise spatial coverage with datasets from across the globe, we acknowledge that geographical biases inevitably exist $^{47}$. For example, we have multiple datasets from the Palearctic, Indomalayan, and Neotropical realms, whereas very little data originated from the Afrotropical region (Figure 3). We also encountered similar coverage bias in country-level data richness, for example, Indonesia is one of the most diverse countries for estimated cave-dwelling bat species richness ${ }^{17}$, but a very small number of species were included in the current version of the database. The database is intended as a long-term data-sharing platform, and we hope to fill these gaps in the next versions of the database. Further data and coverage will provide a better index for regional prioritisation in addition to further research on bat diversity patterns and threats.

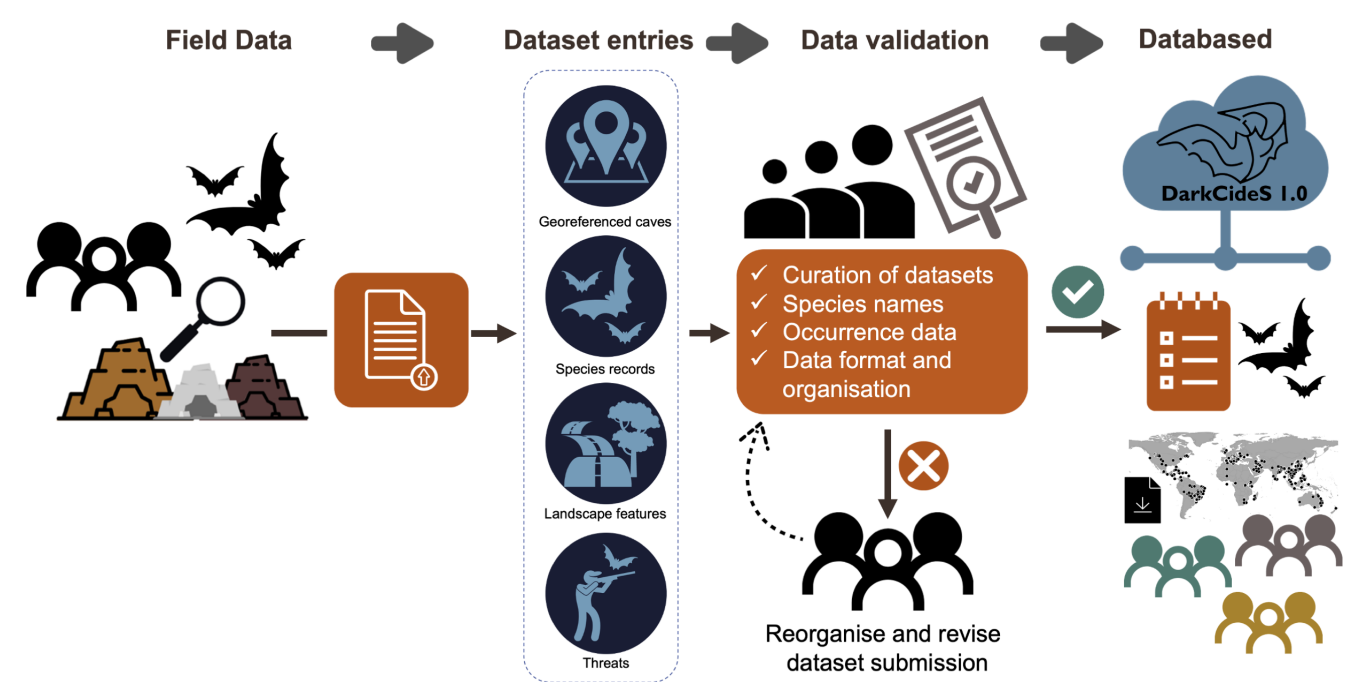

Figure 5: Schematic diagram showing the s updating workflow of the database from new data entry. The DarkCideS database aims to be a long-term biodiversity data exchange platform by including new data from fieldwork and assessments. Authors can upload their dataset containing species data, geographical information, and landscape threats on the web page. The new data will be received by the corresponding authors for validation before being merged into the database.

\section{Code Availability}

No code or costume code was used to generate the data presented in this data paper.

\section{Acknowledgements}

This research project is supported by the Chinese National Natural Science Foundation (Grant No. U1602265, Mapping Karst Biodiversity in Yunnan), the Strategic Priority Research Program of the Chi- 
nese Academy of Sciences (Grant No. XDA20050202), the Chinese Academy of Sciences Southeast Asia Biodiversity Research Center fund (Grant No. Y4ZK111B01). This work is part of the Doctoral project of KCT supported by the University of Chinese Academy of Sciences and Chinese Government Scholarship council, P.R. China (CGS No. 2018SLJ023249) and the Zukunftskolleg Connect Fellowship at the University of Konstanz. DH is supported by the U.S. National Science Foundation (Grant No. DEB-2127290), and by the Research Foundation-Flanders (Junior Postdoctoral Fellowship No. 1206620N) for his project "Laboulbeniales hyperparasitic fungi of bat flies: host specificity and patterns of speciation". FG was supported by the São Paulo Research Foundation-FAPESP (Grant No. 2017/24252-0, 2019/00648-7). RLM was supported by Bryce Carmine and Anne Carmine (née Percival), through the Massey University Foundation. AOA was financed by a postdoctoral grant from Coordenação de Aperfeiçoamento de Nível Superior (CAPES) and Fundacão de Amparo à Ciência e Tecnologia do Estado do Pernambuco (FACEPE). PWW is supported by the U.S. Agency for International Development (USAID) and the US National Academies of Sciences, Engineering, and Medicine under the Partnerships for Enhanced Engagement in Research (PEER) Program. JB is supported by the Coordenação de Aperfeiçoamento de Pessoal de Nível Superior- Brasil (CAPES) (Finance Code 001). Proyecto CUBABAT is supported by the participants of Animal Experience International (https://www.animalexperienceinternational.com/batsincuba) along with funding from The Antonio Núnez Jiménez Foundation for Nature and Humanity (FANJ); Empresa Nacional para la Protección de la Flora y la Fauna (ENPFF), Cuba; el Centro de Servicios Ambientales de Matanzas (CSAM); and The Ministry of Science, Technology and Environment of the Republic of Cuba (CITMA). HFMO was supported by a PhD scholarship and a postdoctoral fellowship from the Coordenação de Aperfeiçoamento de Pessoal de Nível Superior-CAPES (Coordination for the Improvement of Higher Education Personnel; CAPES and CAPES-PRINT). LHDS was supported by a MSc scholarship from the Coordenação de Aperfeiçoamento de Pessoal de Nível Superior-CAPES. The field work was supported by Fundação de Amparo a Pesquisa de Minas Gerais, Spelayon Consultoria, Carste Ciência Ambiental and Anglo American Brasil. We thank Fu Wuxiang and Chen Huanhua for organising our datasets from Chinese literature.

\section{Authors contributions}

$\mathrm{KCT}$, JAG, and ACH conceived and primarily developed the database, with funding acquired by ACH. Data collection, organisation, and formatting were led by $\mathrm{KCT}$ and $\mathrm{ACH}$. $\mathrm{ACH}$ performed the landscape feature mapping and analyses. Data on bat parasites and hyperparasites were compiled and curated by $\mathrm{DH}$. The first draft of the manuscript was written by KCT and $\mathrm{ACH}$. KCT performed data visualisation. All authors provided inputs and suggestions on the draft and approved the final manuscript. The majority of the authors provided data to at least one of the DarkCideS datasets.

\section{Competing interests}

The authors declare no competing interests.

\section{References}

1. Brooks, T. M. et al. Habitat Loss and Extinction in the Hotspots of Biodiversity. Conserv. Biol. 16, 909-923 (2002).

2. Vos, J. M. D., Joppa, L. N., Gittleman, J. L., Stephens, P. R. \& Pimm, S. L. Estimating the normal background rate of species extinction. Conserv. Biol. 29, 452-462 (2015).

3. Heberling, J. M., Miller, J. T., Noesgaard, D., Weingart, S. B. \& Schigel, D. Data integration enables global biodiversity synthesis. Proc. Natl. Acad. Sci. 118, (2021).

4. Ripple, W. J. et al. Extinction risk is most acute for the world's largest and smallest vertebrates. Proc. Natl. Acad. Sci. 114, 10678-10683 (2017).

5. Hughes, A. C., Orr, M. C., Yang, Q. \& Qiao, H. Effectively and accurately mapping global biodiversity patterns for different regions and taxa. Glob. Ecol. Biogeogr. 30, 1375-1388 (2021). 
6. Clark, J. A. \& May, R. M. Taxonomic Bias in Conservation Research. Science 297, 191-192 (2002).

7. Hughes, A. C., Qiao, H. \& Orr, M. C. Extinction Targets Are Not SMART (Specific, Measurable, Ambitious, Realistic, and Time Bound). BioScience 71, 115-118 (2021).

8. Bellon, A. M. Does animal charisma influence conservation funding for vertebrate species under the US Endangered Species Act? Environ. Econ. Policy Stud. 21, 399-411 (2019).

9. Ford, A. T., Cooke, S. J., Goheen, J. R. \& Young, T. P. Conserving Megafauna or Sacrificing Biodiversity? BioScience 67, 193-196 (2017).

10. Simmons, N. \& Cirranello, A. Bat species of the World: A taxonomic and geographic database. https://batnames.org/ (2020).

11. Frick, W. F., Kingston, T. \& Flanders, J. A review of the major threats and challenges to global bat conservation. Ann. N. Y. Acad. Sci. 1469, 5-25 (2020).

12. Furey, N. M. \& Racey, P. A. Conservation Ecology of Cave Bats. in Bats in the Anthropocene: Conservation of Bats in a Changing World (eds. Voigt, C. C. \& Kingston, T.) 463-500 (Springer International Publishing, 2016). doi:10.1007/978-3-319-25220-9_15.

13. Mammola, S. et al. Scientists' Warning on the Conservation of Subterranean Ecosystems. BioScience 69, 641-650 (2019).

14. Whitten, T. Applying ecology for cave management in China and neighbouring countries. J. Appl. Ecol. 46, 520-523 (2009).

15. Ferreira, R. L. \& Martins, R. P. Trophic structure and natural history of bat guano invertebrate communities, with special reference to Brazilian caves. Trop. Zool. 12, 231-252 (1999).

16. Ferreira, R. L. Chapter 57 - Guano communities. in Encyclopedia of Caves (Third Edition) (eds. White, W. B., Culver, D. C. \& Pipan, T.) 474-484 (Academic Press, 2019). doi:10.1016/B978-012-814124-3.00057-1.

17. Tanalgo, K., Oliveira, H. \& Hughes, A. Developing global vulnerabilities and conservation priorities for cave-dwelling bats. https://www.researchsquare.com (2021) doi:10.21203/rs.3.rs-492875/v1.

18. Hughes, A., Orr, M., Yang, Q. \& Qiao, H. Effectively and accurately mapping global biodiversity patterns for different regions and taxa. Glob. Ecol. Biogeogr. (2020) doi:10.22541/au.159654424.40253314.

19. Keith, D. A. et al. The IUCN Red List of Ecosystems: Motivations, Challenges, and Applications. Conserv. Lett. 8, 214-226 (2015).

20. Tanalgo, K. C., Tabora, J. A. G. \& Hughes, A. C. Bat cave vulnerability index (BCVI): A holistic rapid assessment tool to identify priorities for effective cave conservation in the tropics. Ecol. Indic. 89, 852-860 (2018).

21. UNEP/EUROBATS. UNEP/EUROBATS | Agreement on the Conservation of Populationsof European Bats. https://www.eurobats.org/ (2020).

22. Olson, D. M. et al. Terrestrial Ecoregions of the World: A New Map of Life on EarthA new global map of terrestrial ecoregions provides an innovative tool for conserving biodiversity. BioScience 51, 933-938 (2001).

23. Ceballos, G. \& Ehrlich, P. R. Mammal Population Losses and the Extinction Crisis. Science 296, 904-907 (2002).

24. Faurby, S. et al. PHYLACINE 1.2: The Phylogenetic Atlas of Mammal Macroecology. Ecology 99, 2626-2626 (2018).

25. Pacifici, M. et al. Generation length for mammals. Nat. Conserv. 5, 89-94 (2013).

26. Wilman, H. et al. EltonTraits 1.0: Species-level foraging attributes of the world's birds and mammals. Ecology 95, 2027-2027 (2014).

27. Salafsky, N. et al. A Standard Lexicon for Biodiversity Conservation: Unified Classifications of Threats and Actions. Conserv. Biol. 22, 897-911 (2008).

28. Phelps, K., Jose, R., Labonite, M. \& Kingston, T. Correlates of cave-roosting bat diversity as an effective tool to identify priority caves. Biol. Conserv. 201, 201-209 (2016).

29. Simard, M., Pinto, N., Fisher, J. B. \& Baccini, A. Mapping forest canopy height globally with spaceborne lidar. J. Geophys. Res. Biogeosciences 116, (2011).

30. Crowther, T., Glick, H. \& Covey, K. Global tree density map. https://elischolar.library.yale.edu/yale_fes_data/1/(2015).

31. Yamazaki, D., Trigg, M. A. \& Ikeshima, D. Development of a global $\sim 90 \mathrm{~m}$ water body map using multi-temporal Landsat images. Remote Sens. Environ. 171, 337-351 (2015).

32. Song, X.-P. et al. Global land change from 1982 to 2016. Nature 560, 639-643 (2018). 
33. Meijer, J. R., Huijbregts, M. A. J., Schotten, K. C. G. J. \& Schipper, A. M. Global patterns of current and future road infrastructure. Environ. Res. Lett. 13, 064006 (2018).

34. Labay, K. et al. Global Distribution of Selected Mines, Deposits, and Districts of Critical Minerals. (2017) doi:10.5066/F7GH9GQR.

35. Earth at Night (Black Marble) 2016 Color Maps. https://www.visibleearth.nasa.gov/images/144898/earthat-night-black-marble-2016-color-maps (2019).

36. Maggi, F., Tang, F. H. M., Cecilia, D. la \& McBratney, A. PEST-CHEMGRIDS, global gridded maps of the top 20 crop-specific pesticide application rates from 2015 to 2025. Sci. Data 6, 1-20 (2019).

37. Hughes, A. C. Understanding and minimizing environmental impacts of the Belt and Road Initiative. Conserv. Biol. 33, 883-894 (2019).

38. SEDAC. Population Density, v4: Gridded Population of the World (GPW), v4 | SEDAC. (2020).

39. Carlson, C. J. et al. A global parasite conservation plan. Biol. Conserv. 250, 108596 (2020).

40. Haelewaters, D. et al. Parasites of parasites of bats: Laboulbeniales (Fungi: Ascomycota) on bat flies (Diptera: Nycteribiidae) in central Europe. Parasit. Vectors 10, 96 (2017).

41. de Groot, M. D. et al. On the Fly: Tritrophic Associations of Bats, Bat Flies, and Fungi. J. Fungi 6, $361(2020)$.

42. Dick, C. \& Graciolli, G. Checklist of World Streblidae (Diptera: Hippoboscoidea). (2018).

43. Graciolli, G. \& Dick, C. Checklist of World Nycteribiidae (Diptera: Hippoboscoidea). (2018).

44. Index Fungorum. Index Fungorum. http://www.indexfungorum.org/names/names.asp.

45. Haelewaters, D., Hiller, T. \& Dick, C. W. Bats, Bat Flies, and Fungi: A Case of Hyperparasitism. Trends Parasitol. 34, 784-799 (2018).

46. Haelewaters, D., Dick, C. W., Cocherán Pittí, K. P., Dittmar, K. \& Patterson, B. D. Bats, Bat Flies, and Fungi: Exploring Uncharted Waters. in 50 Years of Bat Research: Foundations and New Frontiers (eds. Lim, B. K. et al.) 349-371 (Springer International Publishing, 2021). doi:10.1007/9783-030-54727-1 21.

47. Hortal, J. et al. Seven Shortfalls that Beset Large-Scale Knowledge of Biodiversity. Annu. Rev. Ecol. Evol. Syst. 46, 523-549 (2015). 


\begin{tabular}{|c|c|c|c|c|c|}
\hline Trait category & Trait & $\begin{array}{l}\text { Variable } \\
\text { type }\end{array}$ & Data Filters & $\begin{array}{c}\mathrm{N} \\
\text { Species }\end{array}$ & Source \\
\hline \multirow[t]{6}{*}{ Habitat preference } & Forest & Binomial & Yes $=1$, No $=0$ & 586 & $\begin{array}{c}\text { IUCN } \\
\text { database }\end{array}$ \\
\hline & Savanna & & & 140 & \\
\hline & Desert & & & 45 & \\
\hline & Urban & & & 16 & \\
\hline & Underground & & & 523 & \\
\hline & Wetlands & & & 56 & \\
\hline \multirow{21}{*}{$\begin{array}{c}\text { Ecological status and } \\
\text { distribution }\end{array}$} & Population.status & Nominal & Decreasing & 150 & \\
\hline & & & Stable & 161 & \\
\hline & & & Increasing & 6 & \\
\hline & & & Unknown & 362 & \\
\hline & Conservation.status & & Data.Deficient & 83 & \\
\hline & & & Least.Concern & 452 & \\
\hline & & & Near.Threatened & 54 & \\
\hline & & & Vulnerable & 54 & \\
\hline & & & Endangered & 25 & \\
\hline & & & $\begin{array}{l}\text { Criti- } \\
\text { cally.Endangered }\end{array}$ & 11 & \\
\hline & $\begin{array}{c}\text { Geopoliti- } \\
\text { cal.endemism }\end{array}$ & & Non.Endemic & 459 & \\
\hline & & & Endemic & 220 & \\
\hline & Island.endemism & & Island.Endemic & 159 & Phylacine 1.2 \\
\hline & & & Mainland & 520 & \\
\hline & $\begin{array}{c}\text { Biogeo- } \\
\text { graphic.breadth }\end{array}$ & & Afrotropical & 102 & \\
\hline & & & Indomalayan & 184 & \\
\hline & & & Austral-Oceania & 49 & \\
\hline & & & Neotropical & 173 & \\
\hline & & & Palearactic & 85 & \\
\hline & & & Neactic & 18 & \\
\hline & & & Cosmopolitan & 68 & \\
\hline \multirow[t]{3}{*}{ Feeding groups } & Feeding.groups & & Carnivore & 553 & $\begin{array}{c}\text { EltonTraits } \\
1.0\end{array}$ \\
\hline & & & Frugi-nectarivore & 60 & \\
\hline & & & Omnivore & 66 & \\
\hline \multirow[t]{2}{*}{ Geographical range } & Current.range & Continuous & $\mathrm{N} / \mathrm{A}$ & 679 & Phylacine 1.2 \\
\hline & Natural.range & Continuous & $\mathrm{N} / \mathrm{A}$ & 679 & \\
\hline \multirow[t]{2}{*}{ Biological traits } & Generation.length & Continuous & $\mathrm{N} / \mathrm{A}$ & 679 & \\
\hline & Body.mass & Continuous & $\mathrm{N} / \mathrm{A}$ & 679 & \\
\hline \multirow[t]{10}{*}{ Direct threats } & Mining.quarrying & Binomial & Yes $=1$, No $=0$ & 155 & $\begin{array}{c}\text { IUCN } \\
\text { database }\end{array}$ \\
\hline & Sacred.activities & & & 11 & \\
\hline & Tourism.caving & & & 226 & \\
\hline & Guano.extraction & & & 69 & \\
\hline & Vandalism & & & 106 & \\
\hline & Nest.harvesting & & & 5 & \\
\hline & Hunting.bushmeat & & & 109 & \\
\hline & Intensional.killings & & & 48 & \\
\hline & Gating & & & 7 & \\
\hline & Scientific.research & & & 7 & \\
\hline \multirow[t]{5}{*}{ Indirect threats } & $\begin{array}{c}\text { Agricul- } \\
\text { tural.conversion }\end{array}$ & & & 155 & \\
\hline & Urbanisation & & & 76 & \\
\hline & Deforestation & & & 284 & \\
\hline & Pollution & & & 65 & \\
\hline & Road.kills & & & 12 & \\
\hline \multirow[t]{6}{*}{ Natural threats } & Disease.parasites & & & 5 & \\
\hline & Invasive.species & & & 21 & \\
\hline & Fires & & & 36 & \\
\hline & Drought & & & 9 & \\
\hline & Extreme.cold & & & 1 & \\
\hline & Storm & & & 17 & \\
\hline
\end{tabular}

Table 1: DarkCideS 1.0 includes key traits for all living cave-dwelling bat species $(N=679)$. General metadata for traits included in the current version of the database: habitat preference, ecological status, feeding groups, geographical range, island endemism, geopolitical endemism, distribution range, biogeographical breadth, generation length, body mass, and threatening process. 


\begin{tabular}{|c|c|}
\hline Data.Column & Data Type \\
\hline $\begin{array}{l}\text { Biogeographi- } \\
\text { cal.realm }\end{array}$ & Nominal \\
\hline Biome.classification & Nominal \\
\hline Country.record & Nominal \\
\hline Latitude & $\begin{array}{c}\text { Continuous (WGS } 84 \text { in } \\
\text { DD) }\end{array}$ \\
\hline Longitude & $\begin{array}{c}\text { Continuous (WGS } 84 \text { in } \\
\text { DD) }\end{array}$ \\
\hline
\end{tabular}

$\begin{array}{cc}\text { Data Filters } & \begin{array}{c}\mathrm{N} \\ \text { Species }\end{array} \\ \text { Afrotropical } & \\ \text { Indomalayan } & \\ \text { Austral-Oceania } & \text { Neotropical } \\ \text { Palearctic } & \text { Nearctic } \\ \text { Deserts \& Xeric Shrublands = DES } & \\ \text { Flooded Grasslands \& Savannas = FLO } & \\ \text { Mangroves = MAN } & \\ \text { Mediterranean Forests, Woodlands \& Scrub }=\text { MFWS } \\ \text { Montane Grasslands \& Shrublands = MGS } \\ \text { Temperate Broadleaf \& Mixed Forests = TBMF } \\ \text { Temperate Conifer Forests = TCF } \\ \text { Temperate Grasslands, Savannas \& Shrublands = TGSS } \\ \text { Tropical \& Subtropical Coniferous Forests = TSCF } \\ \text { Tropical \& Subtropical Dry Broadleaf Forests = TSDB } \\ \text { Tropical \& Subtropical Grasslands, Savannas \& Shrublands } \\ \text { = TSGS } \\ \text { Tropical \& Subtropical Moist Broadleaf Forests = TSMB } \\ \text { All country } \\ \text { N/A } \\ \text { N/A }\end{array}$

Table 2: Metadata of the georeferenced information of cave-dwelling bats and caves.

\begin{tabular}{|c|c|c|c|}
\hline Variables & Variable type & Data Filters & References \\
\hline Biogeographical.realm & Nominal & Afrotropical & $\mathrm{N} / \mathrm{A}$ \\
\hline & & Indomalayan & \\
\hline & & Austral-Oceania & \\
\hline & & Neotropical & \\
\hline & & Palearctic & \\
\hline & & Nearctic & \\
\hline Region & & All continents entered & \\
\hline Country & & All countries entered & \\
\hline Cave Name & & All cave names entered & \\
\hline Latitude & Continuous (WGS84 DD) & $\mathrm{N} / \mathrm{A}$ & \\
\hline Longitude & Continuous (WGS84 DD) & $\mathrm{N} / \mathrm{A}$ & \\
\hline Canopy cover & Continuous (see source for units) & Canopy.cov & 25 \\
\hline Tree density & & Tree.dens & 26 \\
\hline Distance to freshwater bodies & & Freshwater.dist & 27 \\
\hline Bare ground cover change & & Bareground.change & 28 \\
\hline Short vegetation cover change & & Shortveg.change & 28 \\
\hline Tall tree cover change & & Talltree.change & 28 \\
\hline Distance to urban areas & & Urban.dist & 28 \\
\hline Distance to roads & & Road.dist & 29 \\
\hline Mine density & & Mine.dens & 30 \\
\hline Nightlight & & Nightlight & 31 \\
\hline Relative pesticide exposure & & Pesticide.exp & 32 \\
\hline Population density & & Pop.dens & 33,34 \\
\hline
\end{tabular}

Table 3: Landscape features included in the current version of the database. 